$\mathrm{mm}, 1 \cdot 5-3 \cdot 49 \mathrm{~mm}$, and $\geqslant 3.5 \mathrm{~mm}$ were $88 \%, 66 \%$, and $47 \%$ respectively. In each thickness group survival was better for women than for men. Overall, the five year survival specific for melanoma was $64 \%$ for the older age group, which is similar to the survival rate reported by other groups for older patients. ${ }^{5}$ For the younger age group overall five year survival specific for melanoma was $78 \%$. With Cox's proportional hazards model the Breslow thickness, ulceration, and sex were found to be the most important prognostic factors. Age above 65 years compared with under 65 was also found to be associated with a significantly poorer prognosis $(\mathrm{p}<0.01)$, independent of Breslow thickness, ulceration, sex, and histogenetic type.

\section{Discussion}

This study confirmed our impression that the pattern of presentation of malignant melanoma is different in elderly patients (65 and over). Several centres, including our own, have embarked on public education exercises aimed at all adults and encouraging early referral of thinner melanomas, which have a better prognosis. ${ }^{6}$ To date no specific message has been aimed at older patients, and our results would suggest that these public education campaigns have not yet reached the over 65 section of the Scottish population, who still have a disturbingly high proportion of thick tumours. A higher proportion of thick tumours in the older age group has been reported by North American groups ${ }^{78}$ and recently from Australia (P Hersey et al, second international symposium on epidemiology of malignant melanoma, Vancouver, 1991). Our figures strongly suggest that public education aimed specifically at older people is required. Education needs to be directed not only at elderly people but also at those who care for them. Campaigns should emphasise that in older people the incidence of melanoma is increasing, particularly in older men; the site most commonly affected in both sexes is the face; and if melanoma is identified early the outlook is still good.

Changing patterns of delivery of health care in the United Kingdom, with greater emphasis on health education and prevention in general practice, mean that this could be an appropriate time to enlist the help of family doctors in a specific programme aimed at informing elderly people about the features of early cutaneous melanoma. This will entail dermatologists offering a preparatory educational programme to general practitioners to help them differentiate true early melanoma from benign non-melanoma pigmented lesions. This programme should also be aimed at district nurses and others involved in the care of elderly patients.

1 Balch CM, Soong SJ, Shaw HM. A comparison of worldwide melanoma data In: Balch CM, Milton GW. Cutaneous melanoma. Philadelphia: Lippincott, In: B.

2 Breslow A. Thickness, cross sectional area and depth of invasion in the prognosis of cutaneous melanoma. Ann Surg 1970;172:902-8.

prognosis of cutaneous melanoma. Ann Surg 1970;172:902-8.
Cox DR. The analysis of binary data. London: Methuen, 1970.

3 Cox DR. The analysis of binary data. London: Methuen, 1970. Kournal of the American Statistical Association 1958;53:457-81.
forlan EL, Meier P. Non-parametric estimation from incomple

5 Shaw HM, McGovern VJ, Milton GW, Farago GA, McCarthy WH. Malignan melanoma: influence of site of lesion and age of patient in the female superiority in survival. Cancer 1980;46:2731-5.

6 Doherty VR, Mackie RM. Experience of a public education programme on early detection of cutaneous malignant melanoma. BMf 1988;297:388-91.

7 Rivers JK, Kelly MC, Kopf AW, Welkovich B, Bart RS. Age and malignan melanoma: comparison of variables in different age groups. $\mathcal{f}$ Am Acad Dermato 1989;21:717-22.

8 Cohen HJ, Cox E, Manton K, Woodbury M. Malignant melanoma in the elderly. F Clin Oncol 1987;5:100-6.

(Accepted 13 fanuary 1992)

\title{
Home based care and standard hospital care for patients with severe mental illness: a randomised controlled trial
}

\author{
M Muijen, I Marks, J Connolly, B Audini
}

\section{Abstract}

Objective-To compare the efficacy of home based care with standard hospital care in treating serious mental illness.

Design-Randomised controlled trial.

Setting-South Southwark, London.

Patients -189 patients aged 18-64 living in catchment area. 92 were randomised to home based care (daily living programme) and 97 to standard hospital care. At three months' follow up $\mathbf{6 8}$ home care and 60 hospital patients were evaluated.

Main outcome measures-Use of hospital beds, psychiatric diagnosis, social functioning, patients' and relatives' satisfaction, and activity of daily living programme staff.

Results - Home care reduced hospital stay by $80 \%$ (median stay six days in home care group, 53 days in hospital group) and did not increase the number of admissions compared with hospital care. On clinical and social outcome there was a non-significant trend in favour of home care, but both groups showed big improvements. On the global adjustment scale home care patients improved by 26.8 points and the hospital group by 21.6 points (difference $5 \cdot 2$; $95 \%$ confidence interval -1.5 to 12 ). Other rating scales showed similar trends. Home care patients required a wide range of support in areas such as housing, finance, and work. Only three patients dropped out from the programme.
Conclusions-Home based care may offer some slight advantages over hospital based care for patients with serious mental illness and their relatives. The care is intensive, but the low drop out rate suggests appreciation. Changes to traditional training for mental health workers are required.

\section{Introduction}

For about 40 years in most Western countries there has been a steady move away from treating patients with a serious mental illness in mental hospitals to caring for them in the community. ${ }^{12}$ In Britain this trend has been bolstered by official policy. ${ }^{3+}$ Initially, little research evidence was produced to support the advantages of community care, but in the past two decades several controlled studies outside Britain have compared home and inpatient care. ${ }^{56}$ The outcome measures used in the studies varied, but any significant differences consistently favoured the patients cared for at home with greater improvement in clinical symptoms and social functioning and in patients' and relatives' satisfaction. No study found inpatient care to be better on any variable. ${ }^{5}$ At the end of the studies the patients cared for at home still had many symptoms and much disability despite their relatively greater improvement. The importance of continuity of care was illustrated by the gradual loss of gains after withdrawal of home care, even after 14 months of home care. ${ }^{78}$
SE1 1LB.

BMf 1992;304:749-54 
We conducted a randomised controlled study of home based and standard hospital care for seriously mentally ill patients to determine whether the results could be replicated in Britain, which has differently organised health services. The objective was to evaluate the effect of intensive home care compared with hospital care on psychopathology, social functioning, and satisfaction. We report here the outcome at three months, which includes the period during which patients received the most intensive care in both treatment groups.

\section{Subjects and methods}

From October 1987 to December 1989 we recruited patients aged 18-64 who had a serious mental illness and were deemed by an independent psychiatrist to require immediate hospital admission. Patients who were violent, suicidal, or subject to a section of the Mental Health Act were all included. If patients subject to a section were not admitted they were taken off the section. All patients had to be living in or connected with south Southwark (including patients with no fixed abode but with close family ties or attending local statutory services). We excluded patients with a primary addiction (dual diagnosis was accepted) or with a primary diagnosis of organic brain damage.

We included in the study all qualifying patients being admitted for the first time to a psychiatric hospital and $20 \%$ of those with previous admissions to determine the efficacy of comunity based care for long term mentally ill patients. The other $80 \%$ were excluded because the team would not have been able to care for this additional number of patients. Since most patients seen have been admitted previously the proportion of first admissions and readmissions in each group was expected to be about equal.

The total study sample included about $20 \%$ of all people from south Southwark admitted to the Maudsley Hospital. One hundred patients were intended to be included in the home based arm because this seemed the maximum the home care team could care for. Owing to time constraints slightly fewer eventually entered. The study was approved by the ethics committee.

\section{ENTRY AND RANDOMISATION PROCEDURES}

Patients were initially seen by psychiatrists at the emergency clinic, who judged that admission was required for a severe mental illness. This decision was made independent of the study by any of the psychiatrists working in the clinic. Patients meeting the entry criteria were randomised to either home based care or standard inpatient care by the clinician opening the next of a set of numbered opaque envelopes, which had been ordered by using random numbers. A blocked design was used. Separate sets had been prepared for new and readmitted patients. Envelopes for new patients all contained either "daily living programme" or "hospital" care but the set for readmitted patients instructed the exclusion of a patient from the study in $80 \%$ of the envelopes. For the $20 \%$ of patients for whom an "include in study" was drawn an envelope was taken from the new admissions' set. All but three of the study patients were entered at the Maudsley Hospital emergency clinic; the exceptions were randomised by consultants on domiciliary visits. Other patients who required admission after domiciliary visits were also entered into the study but were sent by the consultant psychiatrist to the clinic for admission, where randomisation took place.

All patients and their relatives were asked by the clinic staff before randomisation whether they objected to either hospital or community care, whichever was available. If community care was rejected patients were to be excluded from the study, but this never occurred. After randomisation the research proceedings were explained. If patients objected to being rated, this did not affect their care and they remained in the study.

\section{DAILY LIVING PROGRAMME (HOME BASED CARE)}

The daily living programme team initially consisted of seven psychiatric nurses (a senior nurse, three charge nurses, and three staff nurses), a social worker, a senior registrar in psychiatry, and a whole time equivalent secretary. When a nurse left after a year, he was replaced by a senior occupational therapist.

The consultant psychiatrist responsible for the programme was also responsible for the emergency clinic. Staff liaised with other services inside and outside hospital, including the Maudsley emergency clinic for crisis cover at night; the occupational therapy department for assessments of basic skills; and day centres for daytime activities.

Patients were initially assessed with available relatives in the emergency clinic. The first assessment was usually by a psychiatrist and another health worker. Problems were identified, a physical examination was done, and treatment was prescribed fo most patients. When home care was agreed on patients and relatives were offered a lift home, where living conditions were assessed.

For those patients who required immediate admission the daily living programme staff remained responsible for their care. While on the ward patients were seen frequently by the programme's psychiatrist, the key worker, and other staff. Hospital admission was aimed at brief crisis intervention, and patients were taken home as soon as possible for further care. Patients in a serious state, such as those with suicidal or psychotic behaviour, continued to be seen regularly by the psychiatrist and other staff and interventions could be adjusted on a daily basis.

A team member was allocated as key worker from a rotation within 48 hours of entry. Using a problem solving approach, key workers presented and discussed their patients with the multidisciplinary team for advice and modifications to care plans.

\section{STANDARD HOSPITAL BASED CARE}

Patients randomised to this group received inpatient care in the Bethlem or Maudsley Hospitals. They were admitted to beds of any of the consultants and received no special attention. Follow up care consisted mainly of outpatient appointments.

\section{RATING SCALES}

Psychopathology was measured with the present state examination ${ }^{10}$ and the 24 item brief psychiatric rating scale." Neither of these scales have thresholds denoting serious mental illness but in both the scores increase with severity (from 0 (absence of any symptoms) to over 100 for present state examination and from 24 (absence of psychopathology) to 168 for the rating scale). The social adjustment scale was used to measure social functioning (range of mean for all items is $1-5$, lower score=better functioning), ${ }^{12}$ and the global adjustment scale to measure general functioning (range 1-100, higher score=better functioning). Satisfaction was assessed by the client satisfaction questionnaire (range 8-32, higher score indicating greater satisfaction $)^{1+}$ and relatives satisfaction questionnaire (based on the client satisfaction questionnaire range 13-65, higher score=greater satisfaction).

All questionnaires were administered by independent psychologists. Baseline ratings were obtained within 72 hours of entry and follow up ratings between three and six months after entry. Obtaining a complete 
set of ratings from the patients and relatives on each occasion took a mean of three hours over two interviews. In addition, many patients and relatives defaulted from appointments without informing raters, and many had no telephone. Therefore several repeated visits often had to be made to complete a set of ratings. Ratings at nine and 18 months and the cost-benefit analysis will be reported later.

\section{ANALYSIS}

The daily living programme and hospital groups were compared at baseline and on changes from baseline. Confidence intervals of the absolute difference between changes in the two treatment means from baseline to three to six months indicate the likely size of the differential treatment effects. We also calculated a relative measure of the effect of home treatment (the confidence interval divided by the change in the hospital group).

A $t$ test on the changes in score from baseline was performed, adjusting for individual differences at baseline. For the satisfaction scales absolute scores were compared as no baseline data had been obtained.

\section{Results}

During the 25 month admission period 189 patients were randomised, 92 to the daily living programme and 97 to standard hospital care. Because they turned out not to meet selection criteria, seven patients $(4 \%)$ were excluded after randomisation; six (7\%) in the home care group and one $(1 \%)$ in the hospital group. Of the patients excluded in the home group, two were living outside the area, one had an organic disease at the first assessment, one was pregnant, and one refused to participate (the only patient to do so). One patient in each group was excluded because of absence of psychiatric illness. The higher number of patients excluded in the home care group may be due to closer scrutiny of selection criteria by the daily living programme team and may have led to some selection

TABLE I - Baseline values of demographic data for home care and hospital patients. Results are given for all patients and for those with and without follow up data at three to six months. Figures are numbers (percentages)

\begin{tabular}{|c|c|c|c|c|c|c|}
\hline & \multicolumn{3}{|c|}{ Home care } & \multicolumn{3}{|c|}{ Hospital care } \\
\hline & All $(n=92)$ & $\begin{array}{l}\text { Follow up } \\
(\mathrm{n}=68)\end{array}$ & $\begin{array}{l}\text { No follow up } \\
\quad(n=24)\end{array}$ & All $(n=97)$ & $\begin{array}{l}\text { Follow up } \\
(n=61)\end{array}$ & $\begin{array}{c}\text { No follow up } \\
(\mathrm{n}=36)\end{array}$ \\
\hline Mean (SD) age & $33(11 \cdot 5)$ & $35(11 \cdot 5)$ & $32(11 \cdot 3)$ & $35(10 \cdot 8)$ & $35(10 \cdot 9)$ & $35(9 \cdot 6)$ \\
\hline $\operatorname{Sex}($ No $(\%)$ male $)$ & $48(52)$ & $37(54)$ & $11(46)$ & $46(47)$ & $25(41)$ & $21(58)$ \\
\hline \multicolumn{7}{|l|}{ Ethnic origin: } \\
\hline British or Irish & $57(62)$ & $45(66)$ & $12(50)$ & $63(65)$ & $39(64)$ & $24(67)$ \\
\hline Afro-Caribbean & $23(25)$ & $14(21)$ & $9(38)$ & $20(21)$ & $13(21)$ & $7(19)$ \\
\hline Other & $12(13)$ & $9(13)$ & $3(13)$ & $14(14)$ & $9(15)$ & $5(14)$ \\
\hline First admission & $67(73)$ & $48(71)$ & $19(79)$ & $55(57)$ & $39(64)$ & $16(44)$ \\
\hline Previous admission & $25(27)$ & $20(29)$ & $5(21)$ & $42(43)$ & $22(36)$ & $20(56)$ \\
\hline No home support & $33(36)$ & $24(35)$ & $9(38)$ & $44(45)$ & $25(41)$ & $19(53)$ \\
\hline \multicolumn{7}{|l|}{ Diagnosis: } \\
\hline Schizophrenia & $45(49)$ & $37(54)$ & $8(33)$ & $48(49)$ & $33(54)$ & $15(42)$ \\
\hline Mania & $14(15)$ & $7(10)$ & $7(29)$ & $18(19)$ & $11(18)$ & $7(19)$ \\
\hline Depression & $21(23)$ & $15(22)$ & $6(25)$ & $15(15)$ & $9(15)$ & $6(17)$ \\
\hline Neurosis & $9(10)$ & $6(9)$ & $3(13)$ & $14(14)$ & $7(11)$ & $7(19)$ \\
\hline Unclassifiable & $3(3)$ & $3(4)$ & & $2(2)$ & $1(2)$ & $1(3)$ \\
\hline
\end{tabular}

bias. Numbers were low, however, and unlikely to have affected the results of the study.

\section{BASELINE CHARACTERISTICS}

Table I shows the baseline features of all patients, those with three to six months follow up ratings, and those without ratings at three to six months. Most variables were similar across the two treatment groups. Ethnicity was similar to that of the south Southwark population, with a slight excess of patients from an Afro-Caribbean background.

The baseline results of the present state examination were used for diagnosis. If the index of definition was below 5, an ICD (ninth revision) diagnosis was allocated from the medical notes for the seven patients for whom sufficient information was available. Three patients $(3 \%)$ in the home care group and two $(2 \%)$ in the hospital group had no psychopathology. The distribution of diagnoses in the two groups was comparable (table I). However, some heterogeneity between the treatment groups was present. More patients with previous admissions were allocated to standard hospital than to home care, but the reasons for this are unclear.

Table II shows the scores on the psychiatric rating scales. The scores indicate serious mental illness, as would be expected from patients deemed to require admission, and the two groups had similar profiles. The difficulty of obtaining ratings from patients and relatives led to a high proportion not completing all questionnaires. Patients were defined as missing if no score for the global adjustment scale, brief psychiatric rating scale, or present state examination was available at the three month follow up interview. These data were missing from $24(26 \%)$ of home care patients and $36(36 \%)$ of hospital patients, the higher proportion in the hospital care group being mainly due to a greater loss to follow up among patients with previous admissions and men in this group. Reasons for missing ratings differed between the groups; home care patients mainly refused $(21,88 \%)$, whereas hospital patients either refused $(15,42 \%)$ or were untraceable $(18,50 \%)$, probably as a consequence of lack of clinical follow up in hospital care. In both treatment groups baseline demographic features and rating scores of missing patients were similar to those of patients for whom three month ratings were available.

A large proportion of relatives were also lost to follow up. The severity of condition at baseline as measured by the global adjustment scale was similar for patients whose relatives did or did not rate satisfaction.

HOSPITAL ADMISSIONS

This information was available from hospital records for all patients. As intended in the study design home care patients spent much less time in hospital than did hospital patients (table III). The median stay of home care patients was six days and of hospital group patients 53 days. For 21 (23\%) patients admission was prevented altogether by home care. This is a conser-

TABLE II -Mean (SE) baseline scores for all patients and for patients with ratings at both baseline and at three to six month' follow up

\begin{tabular}{|c|c|c|c|c|c|c|c|c|}
\hline & \multicolumn{4}{|c|}{ Home care } & \multicolumn{4}{|c|}{ Hospital care } \\
\hline & \multicolumn{2}{|c|}{ All patients } & \multicolumn{2}{|c|}{ Patients with follow up ratings } & \multicolumn{2}{|c|}{ All patients } & \multicolumn{2}{|c|}{ Patients with follow up ratings } \\
\hline & No of patients & Score & No of patients & Score & No of patients & Score & No of patients & Score \\
\hline $\begin{array}{l}\text { Brief psychiatric rating scale } \\
\text { (range 24-168) }\end{array}$ & 91 & $52 \cdot 2(1 \cdot 6)$ & 68 & $53.0(1.9)$ & 95 & $51.5(1.4)$ & 61 & $51 \cdot 6(1 \cdot 8)$ \\
\hline $\begin{array}{l}\text { Global adjustment scale } \\
\text { (range } 1-100)\end{array}$ & 91 & $33.0(1.5)$ & 68 & $33 \cdot 2(1 \cdot 8)$ & 95 & $33 \cdot 8(1 \cdot 5)$ & 61 & $33.4(1.9)$ \\
\hline $\begin{array}{l}\text { Social adjustment scale } \\
\text { (range } 1-5)\end{array}$ & 86 & $2.60(0.07)$ & 66 & $2 \cdot 64(0 \cdot 08)$ & 92 & $2 \cdot 70(0 \cdot 06)$ & 60 & $2 \cdot 73(0 \cdot 08)$ \\
\hline $\begin{array}{l}\text { Present state examination } \\
\quad(\text { range } 1->100)\end{array}$ & 89 & $28 \cdot 2(1 \cdot 5)$ & 68 & $28 \cdot 4(1 \cdot 8)$ & 95 & $28 \cdot 4(1.4)$ & 61 & $29 \cdot 2(1 \cdot 8)$ \\
\hline
\end{tabular}


vative estimate as patients admitted overnight before randomisation to home care were counted as home care admissions. The differences between the treatment groups in duration of hospital stay was independent of diagnosis or history of a previous psychiatric admission (table III)

Sixty six home care patients $(72 \%)$ but only 17 control group patients (18\%) spent less than 15 days in hospital, and only two home care patients $(3 \%)$ compared with 33 hospital patients (34\%) stayed the whole three month period in hospital. Within treatment groups, length of admission was very homogeneous. In neither of the groups did admission duration differ significantly for patients with or without any previous psychiatric admissions. Neurotic patients had relatively brief admissions in the home care group but not in the hospital group. Diagnosis and history of previous admission did not confound each other; in both groups the first admission schizophrenic patients stayed in hospital about as long as those with previous admissions. Duration of hospital stay did not vary with ethnicity in either group, again independent of diagnosis or history of previous admission.

The short admissions in the home care group did not lead to large numbers of readmissions. Although 20 $(21 \%)$ home care patients versus $10(10 \%)$ hospital patients were readmitted within three months, this difference is misleading because 33 (34\%) hospital patients had remained continuously in hospital since entering the trial.

\section{CLINICAL AND SOCIAL OUTCOME}

Home care patients improved more than hospital patients on all measures, although confidence intervals were wide. No questionnaire suggested an advantage for hospital care (table IV). Similar trends emerged when diagnostic and admission subgroups were considered. All subgroups of patients improved greatly in both treatment groups, with slight advantages for home care patients, but the differences were significant only for measures of relatives' satisfaction for relatives of new patients $(\mathrm{p}<0.04)$, though numbers were low: $19(40 \%)$ relatives of new home care patients (mean (SE) $55 \cdot 3,(1.6))$ and $10(30 \%)$ of relatives of new standard care patients (mean $48 \cdot 0(3 \cdot 4)$ ) completed the questionnaire.

TABLE III - Mean (SD) number of days spent as inpatients

\begin{tabular}{|c|c|c|c|c|}
\hline & \multicolumn{2}{|c|}{ Home care } & \multicolumn{2}{|c|}{ Hospital care } \\
\hline & No of patients & Mean stay & No of patients & Mean stay \\
\hline All patients & 92 & $12 \cdot 4(17 \cdot 3)$ & 97 & $53 \cdot 4(32 \cdot 5)$ \\
\hline No previous admission & 67 & $11 \cdot 6(18 \cdot 8)$ & 55 & $51.8(33.4)$ \\
\hline Previous admission & 25 & $14 \cdot 5(14 \cdot 5)$ & 42 & $55 \cdot 5(32 \cdot 4)$ \\
\hline \multicolumn{5}{|l|}{ Diagnosis: } \\
\hline Schizophrenia & 45 & $13 \cdot 9(14 \cdot 0)$ & 48 & $50 \cdot 4(33 \cdot 3)$ \\
\hline Mania & 14 & $18 \cdot 7(22 \cdot 8)$ & 18 & $62 \cdot 3(32 \cdot 7)$ \\
\hline Depression & 21 & $9 \cdot 3(11 \cdot 9)$ & 15 & $51 \cdot 5(30 \cdot 6)$ \\
\hline Neurosis & 9 & $5 \cdot 6(9 \cdot 9)$ & 14 & $53.9(35 \cdot 5)$ \\
\hline Unclassifiable & 3 & $2 \cdot 0(2 \cdot 9)$ & 2 & $56.5(42.9)$ \\
\hline
\end{tabular}

During this follow up period no suicides occurred, but one home care patient was charged with homicide. A hospital inquiry cleared the daily living programme from any blame.

\section{SUPPORT FOR HOME CARE PATIENTS}

The mean number of contacts per patient fell from 26 in the first month to 17 during the second and 12 during the third month. Mean time of each contact remained constant at about 40 minutes, independent of diagnosis or history of previous admissions. The main component of care, work in the community, demanded $67 \%$ of patient time in the first month, with $27 \%$ spent on ward visits and $6 \%$ on phone calls. From the second month onwards $90 \%$ of patient time was used for community work, the other components requiring only $5 \%$ each.

Patients with and without previous admissions required similar amounts of time. Schizophrenic, manic, and depressed patients required more care in the first month than neurotic patients (table V). At two months after entry psychotic patients required significantly more contacts and time than neurotic patients, but this difference narrowed subsequently.

TABLE $\mathrm{v}-$ Mean numbers of hours spent monthly by daily living programme staff with patients according to psychiatric diagnosis

\begin{tabular}{lcccc}
\hline Month & Schizophrenia & Mania & Depression & Neurosis \\
\hline 1 & $25 \cdot 2$ & $31 \cdot 3$ & $26 \cdot 3$ & $22 \cdot 8$ \\
2 & $18 \cdot 6$ & 17 & $18 \cdot 6$ & $8 \cdot 8$ \\
3 & $13 \cdot 5$ & $13 \cdot 6$ & $10 \cdot 8$ & 6 \\
\hline
\end{tabular}

Many patients received help with aspects of daily living. Although the proportion of neurotic patients being so supported was slightly lower than that of other diagnostic groups and readmitted patients received slightly more help than new patients (table VI) none of the differences was significant. The programme attempted to help several patients to find work by looking through newspapers with them and setting up training interviews, but the success rate was low. Only very few of the 20 patients who were working and the two who were studying found work through the efforts of the programme. Patients who were competent enough to work seemed to be able to find employment independently.

About $30 \%$ of patients required help with problems such as personal hygiene, shopping, or cooking. Several of these patients needed to be visited daily for several weeks, during which time the necessary skills could be taught and reinforced. Little progress was made in many instances, probably partly because of lack of expertise of staff and partly because some patients were less interested in achieving change. Relatives and friends often received support-for example, information, education, counselling, marital therapy, or practical assistance. Relatives did not necessarily live with or actively support patients.

TABLE IV-Mean (SE) and percentage change from baseline score at three to six months' follow up in patients randomised to home and hospital

\begin{tabular}{|c|c|c|c|c|c|c|c|c|c|}
\hline & \multicolumn{3}{|c|}{ Home care } & \multicolumn{3}{|c|}{ Hospital care } & \multirow{2}{*}{$\begin{array}{l}95 \% \text { Confidence } \\
\text { interval of } \\
\text { difference (home } \\
\text { care-hospital) }\end{array}$} & \multirow[b]{2}{*}{$\mathrm{p}$ Value } & \multirow[b]{2}{*}{$\begin{array}{l}\% \text { Advantage o } \\
\text { home care }\end{array}$} \\
\hline & $\begin{array}{c}\text { No of } \\
\text { patients }\end{array}$ & $\begin{array}{l}\text { Change in } \\
\text { score }\end{array}$ & $\%$ Change & $\begin{array}{c}\text { No of } \\
\text { patients }\end{array}$ & $\begin{array}{l}\text { Change in } \\
\text { score }\end{array}$ & $\%$ Change & & & \\
\hline \multicolumn{10}{|l|}{ Brief psychiatric rating } \\
\hline $\begin{array}{l}\text { scale } \\
\text { Global adjustment scale }\end{array}$ & $\begin{array}{l}68 \\
68\end{array}$ & $\begin{array}{l}13 \cdot 7(2 \cdot 1) \\
26 \cdot 8(2 \cdot 3)\end{array}$ & $\begin{array}{l}26 \\
87\end{array}$ & 61 & $10 \cdot 2(1 \cdot 8)$ & 20 & -1.9 to 9 & $0 \cdot 20$ & $-19 \%$ to $56 \%$ \\
\hline Social adjustment scale & $\begin{array}{l}00 \\
66\end{array}$ & $0.4(0.08)$ & $\begin{array}{l}81 \\
15\end{array}$ & $\begin{array}{l}01 \\
61\end{array}$ & $\begin{array}{l}21 \cdot 6(2.3) \\
0.31(0.08)\end{array}$ & $\begin{array}{l}65 \\
11\end{array}$ & $\begin{array}{l}-1.5 \text { to } 12 \\
-0 \cdot 14 \text { to } 0.32\end{array}$ & $\begin{array}{l}0 \cdot 13 \\
0 \cdot 41\end{array}$ & $\begin{array}{c}-7 \% \text { to } 56 \% \\
-45 \% \text { to } 103 \%\end{array}$ \\
\hline Present state examination & 67 & $15 \cdot 3(1 \cdot 8)$ & 54 & 62 & $12 \cdot 6(1 \cdot 8)$ & 43 & $-2 \cdot 4$ to $8 \cdot 0$ & $0 \cdot 28$ & $-19 \%$ to $63 \%$ \\
\hline \multirow{2}{*}{$\begin{array}{l}\text { Patients' satisfaction at } 3 \\
\text { months } \\
\text { Relatives' satisfaction at } 3 \\
\text { months }\end{array}$} & 61 & $24 \cdot 8(0 \cdot 7)$ & & 54 & $23 \cdot 7(0 \cdot 7)$ & & -0.8 to 3.0 & $0 \cdot 26$ & $-3 \%$ to $13 \%$ \\
\hline & 23 & $53 \cdot 5(1 \cdot 9)$ & & 15 & $48 \cdot 5(2 \cdot 5)$ & & $-1 \cdot 3$ to $11 \cdot 3$ & $0 \cdot 11$ & $-3 \%$ to $23 \%$ \\
\hline
\end{tabular}

*95\% Confidence interval of difference divided by change in hospital group 
TABLE VI -Number (percentage) of patients requiring different types of support from daily living programme team

\begin{tabular}{|c|c|c|c|c|c|c|c|}
\hline & Housing & $\begin{array}{l}\text { Social } \\
\text { security }\end{array}$ & Finance & Forensic & Employment & $\begin{array}{c}\text { Daily living } \\
\text { activities }\end{array}$ & $\begin{array}{l}\text { Support for } \\
\text { relatives }\end{array}$ \\
\hline All patients $(n=92)$ & $40(43)$ & $59(64)$ & $42(46)$ & $16(17)$ & $34(37)$ & $27(29)$ & $59(64)$ \\
\hline New patients $(n=67)$ & $24(36)$ & $39(58)$ & $27(40)$ & $9(13)$ & $24(36)$ & $16(24)$ & $41(61)$ \\
\hline $\begin{array}{l}\text { Previously admitted } \\
(\mathrm{n}=25) \\
\text { No home support }\end{array}$ & $16(64)$ & $20(80)$ & $15(60)$ & $7(28)$ & $10(40)$ & $11(44)$ & $18(72)$ \\
\hline $\begin{array}{l}\quad(n=33) \\
\text { Home support }\end{array}$ & $20(61)$ & $25(76)$ & $19(58)$ & $6(18)$ & $16(48)$ & $11(33)$ & $16(48)$ \\
\hline & $20(34)$ & $35(59)$ & $23(39)$ & $10(17)$ & $18(31)$ & $16(27)$ & $42(71)$ \\
\hline $\begin{array}{c}\text { Schizophrenia } \\
(\mathrm{n}=45)\end{array}$ & $22(49)$ & $34(76)$ & $21(47)$ & $9(20)$ & $17(38)$ & $17(38)$ & $31(69)$ \\
\hline $\operatorname{Mania}(n=14)$ & $9(64)$ & $10(71)$ & $7(50)$ & $2(14)$ & $6(43)$ & $3(21)$ & $9(64)$ \\
\hline Depression $(n=21)$ & $6(29)$ & $11(52)$ & $10(48)$ & $5(24)$ & $7(33)$ & $5(24)$ & $13(62)$ \\
\hline Neurosis $(\mathbf{n}=\mathbf{9})$ & $2(22)$ & $4(44)$ & $3(33)$ & & $2(22)$ & $1(11)$ & $5(56)$ \\
\hline
\end{tabular}

\section{Discussion}

Home care reduced the duration of hospital admissions by $80 \%$. This reduction was not achieved at the expense of worse health in home care patients than in hospital patients. Nevertheless, after three months confidence intervals were wide, which makes it difficult to estimate the size of the effect.

Patients' and relatives' satisfaction tended to favour home care over standard care, though this difference was not significant with the exception of the satisfaction of relatives living with new patients. The relatives' satisfaction questionnaire was completed for only a small proportion of the sample, and this group may not have been representative. This low response rate, due to patients refusing permission to interview relatives and to relatives' refusal, is similar to that in other studies. ${ }^{15}$

Duration of admission was surprisingly consistent within each treatment group, and much longer in standard care patients. The required length of hospita stay was largely unrelated to diagnosis or history of admission, but may depend more on tradition and untested opinion than on any proved efficacy and safety of longer inpatient care.

Early in the programme, hospital admission of home care patients was seen as failure but gradually positive indications for admission were identified. Very psychotic and disturbed patients needed more structure than could be offered at home, and were often a risk to themselves or others. Single people were at higher risk of admission, partly because they had no one to look after them but also because they often presented with more severe problems and lived in poor circumstances. In addition, the lack of night staff on the daily living programme meant that single people had to spend the night alone if hospital admission was considered unnecessary, and their inability to do so was often the decisive factor for admission.

Some aspects of home care were so novel that they were not covered by existing guidelines. This included night telephone duty by the nursing staff. Other problems emerged in the course of the project, such as the role of nurses in traditionally medical decisions such as about admission and discharge and adjustment of drugs. In the daily living programme these decisions were often initiated by the non-medical staff, but they required agreement from medical staff, either the team's senior registrar or psychiatrists working in the emergency clinic.

\section{ACCEPTABILITY OF DAILY LIVING PROGRAMME}

Staff were surprised by the appreciation from patients and relatives of attempts to prevent admission to hospital. We had expected that admission would be demanded as the presenting problems were often severe. After being told that the programme provided constant support, patients and relatives became positive about care at home. Patients or relatives rarely objected to discharge after a brief admission. Family sessions were mainly held in the home and aimed at solving problems created for the family or increasing tolerance of the patient's behaviour.

Only three patients refused further contact with the daily living programme after the first few weeks, and these patients functioned well by then, having entered with acute neurotic conditions which required no further care. Several patients refused to see the team for a while, but returned on their own initiative when they needed help. Drug compliance was poor initially, but improved over time, possibly as a result of education and the development of trust. The programme was well accepted by Afro-Caribbean patients, many of whom were young men with schizophrenia living alone.

\section{OTHER STUDYS}

Our study and the Sydney study ${ }^{16}$ both replicated the Madison project. ${ }^{8}$ Average duration of admission for home care patients requiring admission to hospital was about 16 days in all three studies, but the Madison and Sydney studies did not give admission details for subgroups of patients. Improvement in psychopathology and functioning were impressively similar across these studies. The trends always slightly favoured community care, including greater satisfaction of patients and relatives. None of the studies indicate how home care yields slightly greater benefits than hospital care. Home care might be beneficial because it allows interventions in the natural setting, without any need for acquired skills to generalise from an institutional to a home setting, and without the related problem of institutionalisation. Other important components of home care are case management, coordinating the various care components, and continuity of care.

The relatively large variance of outcome measures in our study and others is related to low power, which may have contributed to the absence of any differential outcome in the various subgroups. Nevertheless, our study included the largest number of patients of studies evaluating home care so far.

A potential criticism of such studies is the role of bias. Some bias is unlikely to be avoided, because clinicians, assessors, and patients cannot be blinded to treatment and may have been influenced by the publicity supporting or condemning community care. The strength and direction of such biases are impossible to measure and may have led to underestimation or overestimation of treatment differences.

\section{REQUIREMENTS FOR HOME CARE}

The clinical experiences suggest that home care requires a different approach towards patient care and flexibility on the part of both clinicians and management. It is not known whether the help given to patients reflected their need, as perceived by either patients or staff, or staff interest or ability to deal with particular problems. The relatively low proportion of success with work and activities of daily living may have been due to lack of staff training and experience since a considerable need existed.

A large amount of time was spent dealing with patients' financial and housing problems, with staff liaising with social services, housing departments, and telephone, gas, and electricity companies. These negotiations were beneficial to patients, who had often been unable to deal with the problems on their own. Such work is traditionally thought to be the responsibility of social workers, suggesting that service caring for severely mentally ill people should be multidisciplinary. Psychiatric patients are particularly prone to problems in these areas, and their poor circumstances can be the result of or aggravate their illness. 
Case management entails acceptance of responsibility for the coordination and implementation of the many required components of care. This may have to continue for many years, and staff will have to accept that care and maintenance may have to be the objective, rather than cure. The low drop out rate of home care patients, reflected in the higher number of untraceable patients in the hospital group, suggests that patients appreciated the attention given to difficulties which affect their quaility of life at least as much as their psychiatric illness. It also suggests that an assertive community team, sensitive to the need of patients can prevent those patients who need the support most from dropping out, as found by other studies. ${ }^{17} 18$ This role for mental health workers differs from the traditional ward role, and training will need to be adjusted.

Comprehensive community care requires resources. The lack of sufficient facilities in an impoverished inner city area imposed a great burden of care on home care staff, and it is doubtful whether such devotion to care could continue indefinitely in community teams. The experience of the Mendota Mental Health Centre suggests that some reduction in enthusiasm can be expected after conversion from a model programme to a regular service, although the centre's continuing effectiveness also indicates that a community service is feasible. ${ }^{19}$ Some community services in Britain confirm this. ${ }^{20}$

The relevance and general applicability of model programmes of home care such as ours depend on many factors, including patient target groups, sociodemographic characteristics of the area, staffing levels, and resources. The external validity of the daily living programme will have to be judged by local clinicians, managers, and planners.

This project was funded by a grant from the Department of Health to I M and J C. Another grant from the department enabled Professor Rosser to help with some of the ratings.
During the last year of the study $M M$ was supported by a Medical Research Council training fellowship.

1 Audit Commission. Making a reality of community care. London: HMSO, 1986.

2 Brown P. The transfer of care. Psychiatric de-institutionalization and its aftermath. New York: Routledge, 1985.

3 Department of Health and Social Security. Better services for the mentally ill. London: HMSO, 1975.

4 Department of Health and Social Security. Caring for people. London: HMSO, 1989

5 Brun P, Kochansky G, Shapiro R, Greenberg S, Gudeman JE, Johnson S, et al. Overview: de-institutionalisation of psychiatric patients, a critical review of Overview: de-instutionalisation of psychiatric pactent

6 Kiesler CA. Mental hospitals and alternative care. Am Psychologist 1982;37: 349-60.

7 Davis AE, Dinitz S, Pasamanick B. The prevention of hospitalisation in schizophrenia: five years after an experimental programm. Am $\mathcal{F}$ Orthopsychiatry 1972;42:375-88.

8 Stein LJ, Test MA. Alternative to mental hospital treatment. 1. Conceptual model, treatment program and clinical evaluation. Arch Gen Psychiatry 1980;37:392-7

9 Marks I, Connolly J, Muijen M. The Maudsley daily living programme: a controlled cost-effectiveness study of community-based versus standard inpatient care of serious mental illness. Bulletin of the Royal College of Psychiatrists 1988;12:22-4

10 Wing JK, Cooper JE, Sartorius N. The description and classification of psychiatric symptoms: an instruction manual for the PSE and Catego system. London: Cambridge University Press, 1974

11 Overall JE, Gorham DR. The brief psychiatric rating scale. Psychol Rep 1962;10:799-812.

12 Weissman MM, Klerman GL, Paykel ES, Prusoff B, Hanson B. Treatment effects on the social adjustment of depressed patients. Arch Gen Psychiatry $1974: 30: 771-8$.

13 Endicott J, Spitzer RL, Fleiss JL, Cohen J. The global assessment scale. A procedure for measuring overall severity of psychiatric disturbance. Arch Gen Psychiatry 1976;33:766-71.

14 Larsen DH, Attkison CC, Hargreaves WA, Nguyen TD. Assessment of client/ patient satisfaction: development of a general scale, Evaluation Progress Planning 1979;2:197-207.

15 Test MA, Stein LI. Alternative to mental hospital treatment. 3. Social cost. Arch Gen Psychiatry 1980;37:409-12.

16 Hoult J, Reynolds I, Charbonneau-Powis M, Weekes P, Briggs J. Psychiatric hospital versus community treatment: the results of a randomised trial. Aust N ZF Psychiatry 1983;17:160-7.

17 Pepper B, Kirschner M, Rylewics $H$. The young adult chronic patient: overview of a population. Hosp Community Psychiatry 1981;32:436-69.

18 Meltzer D, Hale S, Malik SJ, Hogman GA, Wood S. Community care for patients with schizophrenia one year after hospital discharge. BMJ 1991;303:1023-6.

19 Muijen M, McNamee G. A visitor's view of Madison's PACT program and Dane County Mental Health Centre. Bulletin of the Royal College of Psychiatrists 1989;13:352-5.

20 Dean C, Gadd EM. Home treatment for acute psychiatric illness. BMY 1990;301:1021-3.

(Accepted 27 November 1991)

\section{ONE HUNDRED YEARS AGO}

\section{MARAT'S BROTHER.}

It is now well known that Marat was a physician with a considerable practice, and no mere "horse leech," as Carlyle described him, many years before the revolutionary craze made him the shabby, dirty, bloodthirsty personage so familiar to the student of history. Mr. Morse Stevens, in his great work on the French Revolution, now in course of publication, speaks of the "ami du peuple" as an educated gentleman. It also appears, ${ }^{1}$ according to $M$ Germain Bapst, that Marat had a brother Olivier, who played a remarkable part in the history of science in Paris during the Reign of Terror. On the day before the fatal 10th of August, 1792, Louis XVI made Bernardine de St. Pierre, the immortal author of Paul et Virginie, Director of the Jardin des Plantes. He was probably the last man ever appointed to any charge by that monarch. He proved a failure, and was replaced by the veteran Daubenton. The Government had brought the royal menagerie from Versailles to the Jardins des Plantes, and Daubenton himself succeeded in bringing to Paris a fine collection of minerals confiscated at Chantilly, the palace of the emigre Prince de Condé. But soon funds fell low, and the director sent repeated claims for subsidies to the Convention, which turned a deaf ear to his entreaties. The collection would have perhaps been ruined, when suddenly the director found out a way of pressing the Government without risking his own head. Marat had just been killed. His brother Olivier was making an uncertain livelihood at Geneva by collecting and mounting insects. Olivier Marat pressed Soulavie, the French Minister at Geneva, to get him a post at Paris. He was accordingly recommended to Daubenton. The Minister of the Interior sent a similar recommendation to that scientist, with a further request that rooms for Olivier Marat and his wife should be prepared in the Museum. Accordingly Daubenton, De Jussieu, Lamarck, and Saint-Hilaire agreed to the request, but respectfully noted that the Museum was so short of funds that it would not be possible to set up Olivier Marat and his wife in the Museum till debts were paid and a further subsidy granted. The Minister had to present the plea before a Committee of the Convention, and it was granted. The funds were used for arranging the collections in the Museum. The lodgings for the Marats were slowly prepared, when Robespierre fell and Olivier Marat was forgotten. He disappeared from the Jardin des Plantes and from history for ever. (BMF 1892;i:673)

'Germain Bapst, "Histoire d'un Cabinet Minéralogique," Revue des Deux Mondes, March 15th, 1892. 